\title{
'Ultimately the question always is: "What do I have to do to do it right?"' Scripts as explanatory factors of career decisions
}

\section{Grit Laudel}

Technical University of Berlin, Germany

\section{Jana Bielick}

Technical University of Berlin, Germany

\section{Jochen Gläser}

Technical University of Berlin, Germany

\begin{abstract}
In this article, we address one of the recurrent problems of career theory, namely the integration of individual agency and structural conditions of action in explanations of career decisions, and through them, career trajectories and their outcomes. We draw on Barley's suggestion to include scripts as mediating between institutions and individual actions. By theoretically specifying scripts as collectively shared interpretive schemes that describe successful careers, we are able to introduce them as a specific factor that contributes to the explanation of career decisions. We demonstrate with a study of German early career researchers in two fields how scripts can be empirically identified and used in combination with other explanatory factors. Our analysis demonstrates how the concept 'career script' captures a specific social influence on career decisions that is different from rules governing behaviour and individual interests, goals and plans for a career.
\end{abstract}

\section{Corresponding author:}

Grit Laudel, Department of Sociology, Technical University of Berlin, Sekretariat FH 9-I, Fraunhoferstr.

33-36, Berlin, 10587, Germany.

Email: grit.laudel@tu-berlin.de 


\section{Keywords}

academic careers, career decisions, career institutions, career theory, early career, scripts

\section{Introduction}

One of the recurrent problems of career theory is the integration of individual agency and structural conditions of action in explanations of career decisions, and through them, career trajectories and their outcomes (Evetts, 1992; Gunz, 1989; Gunz et al., 2011; Mayrhofer et al., 2007; Tams and Arthur, 2010: 633). This has been illustrated by the discussion about 'boundaryless careers' (Arthur and Rousseau, 1996) and 'protean careers' (Hall, 1996). Both conceptualizations have been criticized as over-emphasizing individual agency at the cost of neglecting the role of institutions (Dany et al., 2011; Inkson et al., 2012). However, the proposal to focus on boundaries rather than boundaryless careers (Inkson et al., 2012) does not solve the underlying problem. The dichotomy of boundaryless and bounded careers just reproduces the structure-agency problem, as does the recognition of the importance of context for boundaryless careers (Tams and Arthur, 2010).

The emergence of career patterns - similarly shaped individual sequences of work experiences in a specific context - from individuals' decisions about their careers is not easily explained by references to boundaries or other institutions like organizational structures. A solution to this problem that has been proposed by Barley (1989) is to include in explanations of career decisions career scripts as social phenomena that mediate between institutions and individual action. The usefulness of the concept of career scripts has been pointed out by several authors (Arthur et al., 1999; Weick, 1996).

Despite these recommendations, the script concept remains heavily under-used and is not applied consistently, which undermines its explanatory power. This is why the concept so far has served the purposes of single studies but is less than ideal for cumulative progress of career theory. We see three problems related to the script concept, which ultimately can be traced back to the ambiguity of definitions. First, unlike concepts like institution or individual agency, the position of 'script' in social theory is not clear and appears to shift with each new article. However, positioning scripts in social theory is crucial for linking career theory and empirical research on careers to other social science fields. Second, the concept of a career script must be defined in a way that makes it a distinct factor that can be integrated in theoretical explanations. Third, the concept needs to be operationalized in a way that supports the empirical search for career scripts, distinguishes between empirical phenomena that are scripts and those that are not, and includes them in empirically grounded arguments.

The aim of our article is to contribute to the use of the script concept as an explanatory factor (i.e. as a conceptualization of a specific influence on career decisions and, through them, on careers and career patterns). We begin by demonstrating that the script concept has been used in many ways that cannot be easily reconciled. This is due to the concept's insufficient specification and operationalization, which is why we first ground 'scripts' in social theory and then specify the concept for careers in general and academic careers 
in particular. We then use empirical data from a study of German early career researchers to demonstrate that such a concept can indeed capture a specific social influence on career decisions.

\section{The script concept in studies of careers}

The notion of career scripts as mediating between institutions and individual actions and the idea that institutions are enacted through scripts have been introduced by Barley (1986, 1989; Barley and Tolbert, 1997). Since most users of the script concept in career studies refer to Barley (1989), we would like to point out two ambiguities of his argument because they are partly responsible for ambiguities of its application. First, Barley treats careers as scripts because his interpretation of the Chicago School's approach sees careers as 'properties of collectives' (1989: 49, 51) and 'abstracts of an individual's history of participation in a social collective' (p. 53), while current career research starts from Hughes' definition of careers as an individual's work experience and uses terms like 'career pattern' for the idea Barley intended to capture (Gunz et al., 2011).

Second, the notion of a script itself remains ambiguous. Barley uses the framework of Giddens' structuration theory and considers scripts as the form in which knowledge about institutions becomes an element of an actor's practical knowledge: 'These elements of practical knowledge, which Giddens calls modalities, can profitably be construed as a set of scripts that encode contextually appropriate behaviors and perceptions' (Barley, 1989: 53). He defines scripts as 'plans for recurrent patterns of actions that define, in observable terms, the essence of actors' roles' (p. 53). Applying this idea to careers, Barley suggests: 'careers can be thought of as temporally extended scripts that mediate between institutions and interactions. Like all scripts, careers should therefore offer actors interpretive schemes, resources and norms' (Barley, 1989: 53, our emphasis). In this statement, it is not clear anymore whether scripts are instances of Giddens' modalities (interpretive schemes, resources, and norms) - and if so, of only one or all three of them - or something else that offers these modalities, which Barley suggests in the quote above. Thus, Barley's discussion of scripts in structuration theory is far from unequivocal.

Career studies have drawn on Barley's suggestions only reluctantly and in a variety of ways, which we ascribe to the ambiguity of Barley's various proposals. To our knowledge, the first to take up this suggestion is Weick (1996), who discusses changes of careers scripts in boundaryless organizations and boundaryless careers. Arthur et al. (1999) also take up the concept. In both cases, however, it is not completely clear whether Barley's original conceptualization is held up (e.g. when Weick includes internal labour markets as career scripts (1996: 45) or when Arthur et al. consider scripts as 'institutionally ... determined programs' (1999: 42).

The script concept has also been used in empirical investigations. Cappellen and Janssens (2010) investigated globally oriented managers in transnationally operating companies. They start from Barley's (1989) definition but then follow Arthur et al. and consider scripts as institutionally determined (2010: 689). Consequently, they construct from their empirical material scripts that are determined by the organizations and distinguish them from career aspirations and perceptions of the individuals enacting the 
careers. The latter, which include reports about 'a broad skill base' or 'knowledge of multiple markets', were interpreted as global context rather than indications of scripts that extend beyond the organization. In their investigation of the role of career scripts for immigrant professionals ('pre-entry scripts'), Zikic and Richardson (2016) defined scripts as 'local rules and procedures encountered by non-organizational members seeking to re-enter into their respective profession' (p. 144), thereby treating scripts as institutions.

Two investigations of women managers' careers started from Barley's (1989) definition (Jacobson and Aaltio-Marjosola, 2001: 232) but ended up using the script concept to capture respondents' individual experiences (Aaltio and Huang, 2007; Jacobson and Aaltio-Marjosola, 2001). The script concept is used to label individual career orientations and personal traits such as being 'flexible' or 'risk-averse', or 'having high future-expectations'.

The same ambiguous and multifaceted use of the script concept can be observed in its application to academic careers. Dany et al. (2011) refer to Barley and Tolbert (1997), among others, but define scripts as 'rules and norms that individuals have in mind when they think of their careers', and the 'promotion scripts' they study as 'individuals' interpretations and reconstructions of the promotion rules and models applied by those in charge of selecting and promoting academics' (Dany et al., 2011: 976). While they argue in the spirit of Barley's proposal, their definition and use of the script concept suggests an understanding of scripts as individuals' interpretations of institutions, which obfuscates the idea of scripts as collectively shared interpretive schemes. In their investigation of careers of public sector researchers in the UK and New Zealand, Duberley and colleagues found patterns of subjective meanings given to careers by the interviewed researchers. They originally labelled these patterns as 'career orientations' (Mallon et al., 2005) and later relabelled them as 'scripts'. For the latter label, they draw on Barley (1989) and emphasize the notion of people interpreting and enacting scripts (Duberley et al., 2006: 1136). They describe 'four scripts which individuals draw on in accounting for their careers' (p. 1139), which reduces scripts to cognitive resources for individual sense-making that may or may not be collectively shared.

These applications of the script concept have in common that they start from Barley's idea but then gravitate either to the institutional pole (equating scripts with institutions) or to the individual pole (equating scripts with individual perceptions). These ambiguities have been criticized by Valette and Culié (2015) as well as Gunz and Mayrhofer (2018: 255). The solution proposed by Valette and Culié resolves the ambiguity of interpretive scheme or behavioural pattern but not the ambiguity of collective or individual phenomenon. It can be interpreted as treating scripts as collective representations that are subject to individual interpretation (2015: 1748-1749) or as treating scripts as a combination of individual, contextual and situational factors (p. 1759). More importantly, 'script' remains a descriptive label for individual perceptions of opportunities for career moves. Although the authors claim to 'explain careers' (pp. 1747, 1756), it is not clear what they explain because the phenomenon career scripts are supposed to influence career decisions - is not studied. Valette and Culié leave this to future work (p. 1761).

This brief account of how the script concept has been used by career studies demonstrates that the concept remains ambiguous, a critique voiced by Valette and Culié (2015: 
2-4). Starting from the same definition, authors tend to interpret it not as an intermediary between institutions and individual actions but as either an institution or an individual interpretive scheme. This outcome seems to be inevitable when a concept that is formulated at a very high level of abstraction of social theory is directly applied to descriptively categorize empirical data without further theoretical specification or empirical operationalization. In particular, it is difficult to see how the concept can contribute to explanations of career decisions or career patterns without further specification.

\section{Positioning scripts in (career) theory}

The preceding review of career studies' uses of the script concept demonstrated that although almost all studies start from the same basic idea, the applications diverge considerably. We argued that this is due to both ambiguities of the abstract concept and to its insufficient theoretical specification for career studies. In this section, we attempt three clarifications by positioning scripts in social theory, specifying the concept for career studies and operationalizing it for the study of academic careers.

\section{Social theory}

Ever since it has been introduced in psychology and sociology, the concept of a script has oscillated in two dimensions. With regard to the level of aggregation, scripts have been defined as either collective or individual properties. With regard to their social quality, they have been defined as cognitive phenomena (interpretive schemes) or behavioural regularities.

On the individual-collective dimension it is not surprising that psychologists applied the concept exclusively to the individual level. Schank and Abelson (1977) observed knowledge structures in a person's daily life that are organized around routine, goal-oriented activities and stored in their memories. These knowledge structures (or mental schemes) describe appropriate sequences of events in a particular context. They called these knowledge structures 'scripts' and defined a script as a 'predetermined, stereotyped sequence of actions that defines a well-known situation' (1977: 41). This implies that scripts determine rather than guide actions. Abelson later deviated from this definition by distinguishing between strong scripts that prescribe a sequence of actions (e.g. for a restaurant visit) and weak scripts that are a 'bundle of inferences about the potential occurrence of a set of events' (Abelson, 1981: 717; see also Gioia and Poole, 1984).

In sociology, Goffman (1959: 70-74) introduced the notion of scripts for his analysis of face-to-face interactions. Goffman, too, treated scripts as individual mental schemes. Participants perform roles that are specific to their situation and thereby follow a social script. These social scripts are similar to a script of a theatre play but less detailed - they leave room for manoeuvre according to an actor's interests. Goffman did not define a sociological concept but merely borrowed the idea of scripts from theatre and used the concept as a metaphor. However, his description of social scripts embeds them in larger social contexts in which they emerge and operate even though Goffman did not concern himself with the analysis of these processes. 


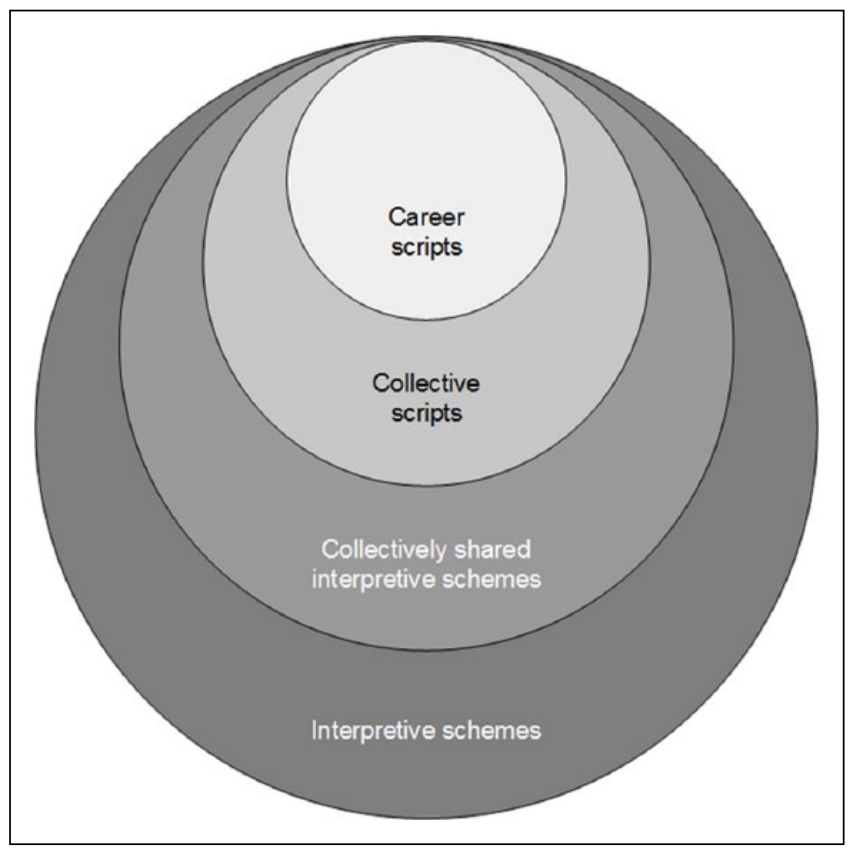

Figure I. Theoretical embedding of career scripts.

The first systematic attempt to introduce a sociological concept of scripts has been undertaken by Barley, who drew on both the psychological and sociological discussions (Barley, 1986: 83). In the 20 years following this introduction of the concept, Barley offered a variety of definitions, which have in common that they treat scripts as collective-level phenomena but otherwise oscillate between behavioural patterns and cognitive schemes. Scripts are seen (a) as patterns of actions ('behavioural regularities' and 'activities and patterns of interaction'; see Barley, 1986; Barley and Tolbert, 1997); (b) as 'plans' for patterns of actions (i.e. cognitive phenomena; Barley, 1989); or (c) as both 'cognitive and behavioural phenomena' (Barley, 2015: 35). Barley also adopts the deterministic notion of scripts, which has only been softened in his recent definition of scripts as 'loosely prescribed sequences of behaviours and interactions associated with types of encounters' (Barley, 2015: 35).

The most important contribution by Barley is his positioning of scripts in social theory as mediating between institutions and actions. Owing to the various inconsistencies, however, a further specification of the concept is required (Figure 1). First, we consider scripts as specific interpretive schemes (Giddens, 1979; Schütz, 1967), which can be defined as specific cognitive structures that provide knowledge about situations and proven solutions for typical problems (Schütz, 1967; Schütz and Luckmann, 1973). These cognitive structures have also been termed frames (Goffman, 1974). In contrast to Barley, we thus consider scripts as only one of Giddens' modalities. 


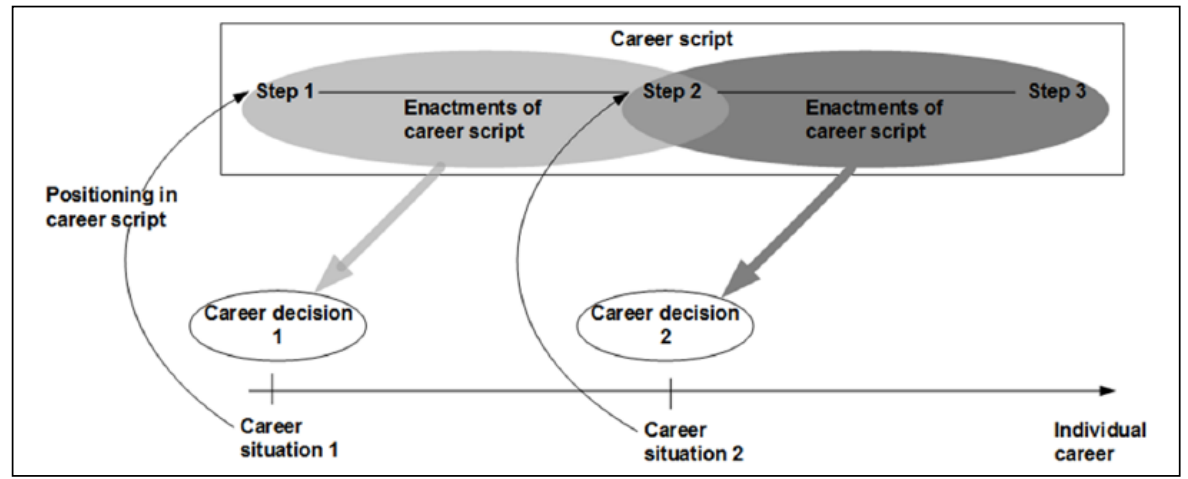

Figure 2. Enactment of scripts in career decisions.

Interpretive schemes are cognitive resources of individuals but some of them are collectively shared. This applies to scripts, too. Some scripts are purely individual interpretive schemes (e.g. a person's morning routine) and may be subconsciously activated, while others are collectively shared. In a second step, we therefore define collective scripts as intersubjectively shared interpretive schemes that encode contextually appropriate behaviours. As collectively shared knowledge structures, collective scripts are communicated between actors, and are often consciously activated. Following Barley and others, we see these collective scripts as related to a specific institutional setting. They mediate between institutions and individual actions because they describe patterns emerging from individual actions that are shaped by these institutions. Scripts are enacted in individual actions. We consider this differentiation between institutions, scripts and their interpretations by individuals as crucial for assigning explanatory potential to the script concept.

Third, career scripts are collective scripts that encode sequences of stages within a career and decisions that are likely to produce these sequences when made in specified situations in a specific institutional setting. This definition is sufficiently specific to distinguish career scripts from other influences on career decisions such as institutions (rules and norms concerning individual behaviour), individual career plans and individual career orientations. This distinction is important because a narrower concept is better suited to the multi-causal nature of sociological explanations as it captures a specific phenomenon (and its variation), which can then be related to other influences in explanations. ${ }^{1}$

An actor usually has knowledge about one or more career scripts that are relevant to their specific institutional environment. When making career decisions in particular situations, actors position themselves in these scripts and decide about the next career move from the perspective of a sequence of moves leading to career progress (Figure 2). Through career decisions, in turn, scripts are maintained or may be altered over time (Barley, 1989; Barley and Tolbert, 1997). In other words, we consider scripts not as institutionally determined but as co-determined by institutions and (mutually observed) individual actions enacting them. 
Table I. Model of academic careers and corresponding scripts.

\begin{tabular}{|c|c|c|}
\hline & Description of career & Content of career script \\
\hline $\begin{array}{l}\text { Cognitive } \\
\text { career }\end{array}$ & $\begin{array}{l}\text { Sequence of thematically } \\
\text { interconnected research processes }\end{array}$ & $\begin{array}{l}\text { Dynamics of originality, relevance, } \\
\text { durability and thematic breadth of research }\end{array}$ \\
\hline $\begin{array}{l}\text { Community } \\
\text { career }\end{array}$ & $\begin{array}{l}\text { Sequence of statutes and } \\
\text { associated work roles in one's } \\
\text { scientific community }\end{array}$ & $\begin{array}{l}\text { Accumulation of reputation and sequence } \\
\text { of statuses in one's scientific community }\end{array}$ \\
\hline $\begin{array}{l}\text { Organizational } \\
\text { career }\end{array}$ & $\begin{array}{l}\text { Sequence of organizational } \\
\text { positions as sets of rather } \\
\text { unspecific work roles }\end{array}$ & $\begin{array}{l}\text { Sequence of organizational positions which } \\
\text { support a stable academic career and } \\
\text { success in all three careers }\end{array}$ \\
\hline
\end{tabular}

\section{Operationalization of the script concept for academic careers}

The specification of the script concept for careers of researchers must take into account the special role the content of work plays for academic careers. One of the peculiarities of research, which sets it apart from most other work, is its production of and embeddedness in diachronic knowledge structures that extend throughout an academic's research biography and unfold over time. These diachronic knowledge structures are sequences of research processes that build on each other because the knowledge produced in previous research processes informs the choices of research problems and approaches in subsequent research. Research in the sciences, social sciences and humanities differs from much other organized work because it builds and depends on these diachronic structures, which transcend the institutional boundaries set by the sequence of organizational positions.

A second peculiarity of research is that although most of today's research is conducted in organizations, the primary work context of researchers is their scientific community rather than their employment organization (Whitley and Gläser, 2014). Scientific communities and the body of knowledge they jointly advance are the primary referent for the formulation of tasks, the standards of conduct and the evaluation of results. The role of work content and community for careers has been noted for knowledge workers in general (DeFillippi et al., 2006). Research, however, is specific knowledge work that creates diachronic structures of work that are bound to the individual researchers and derives its tasks from and addresses results to the community.

Both the content of work - the knowledge production researchers are engaged in and their position in their scientific communities contribute to shaping academic careers. Consequently, the understanding of careers as a sequence of work-related experiences, which is suggested by the Chicago School (Barley, 1989; Hughes, 1958), must be applied to the sequence of stages in the production of knowledge, to the sequence of status positions in the scientific community (in line with the conceptualization of professional careers; Dalton et al., 1977; Zabusky and Barley, 1997) and to the sequence of organizational positions simultaneously. We then arrive at a model that analytically distinguishes between three interrelated careers of a researcher, namely the cognitive career, the community career and the organizational career. ${ }^{2}$ Each of the careers in this tripartite model has its own scripts. Table 1 describes the careers and the subject matter of career scripts that can be derived from them: 
(1) The cognitive career consists of thematically connected problem solving processes in which findings from earlier research projects serve as input in later projects. These connected problem solving processes constitute one or several distinct 'research trails' (Chubin and Connolly, 1982). They form a diachronic structure that gradually extends a researcher's knowledge base over time. The evolution of the content of research has distinct stages and structures, and is closely linked to other career experiences. The script of the cognitive career is an interpretive scheme that reflects the originality, relevance, durability and (often increasing) thematic breadth of research.

(2) The community career consists of specific stages of reputation and corresponding role expectations of researchers in their scientific community. An apprentice learns to conduct research while working under the direction of others. PhD students are usually apprentices, in some cases this stage may extend to early postdoctoral phases. A colleague conducts independent research (i.e. autonomously decides on problems to solve), on approaches to problem solving, and on ways to communicate results to the scientific community. A master additionally acts as a teacher of apprentices. A member of the elite additionally shapes the direction of the knowledge production of their community. The community script is an interpretive scheme that reflects the continuous gaining of reputation and the sequence of statuses within the scientific community.

(3) The organizational career (which so far has been the almost exclusive concern of career studies) is a sequence of organizational positions that couple organizational role expectations concerning research and other tasks with salaries and access to resources for conducting research. The script of an organizational career is an interpretive scheme that reflects sequences of organizational positions that are typically successful in achieving specific career goals. Although the script describes a sequence of organizational positions, its source is the scientific community rather than any organization. This is not surprising, since academic careers usually cross the boundaries of formal organizations (Baruch and Hall, 2004).

The three careers and their scripts operate as resources and constraints for each other and must therefore be aligned to some extent. For example, each organizational position usually corresponds to a certain status within the community. The reputation and status acquired depends on progress in the cognitive career, which in turn requires organizational positions and access to resources.

Since the content of work strongly influences academic careers, careers and their scripts are likely to be specific for the research field in which the career takes place. Such a research field-dependent specification of scripts is part of the empirical case studies we present in the following section.

\section{Explaining decisions of German early career researchers}

This conceptual framework can now be used to integrate scripts for the three careers in explanations of career decisions. We use interviews with German early career researchers from a project that explored the emergence of individual research programmes by 


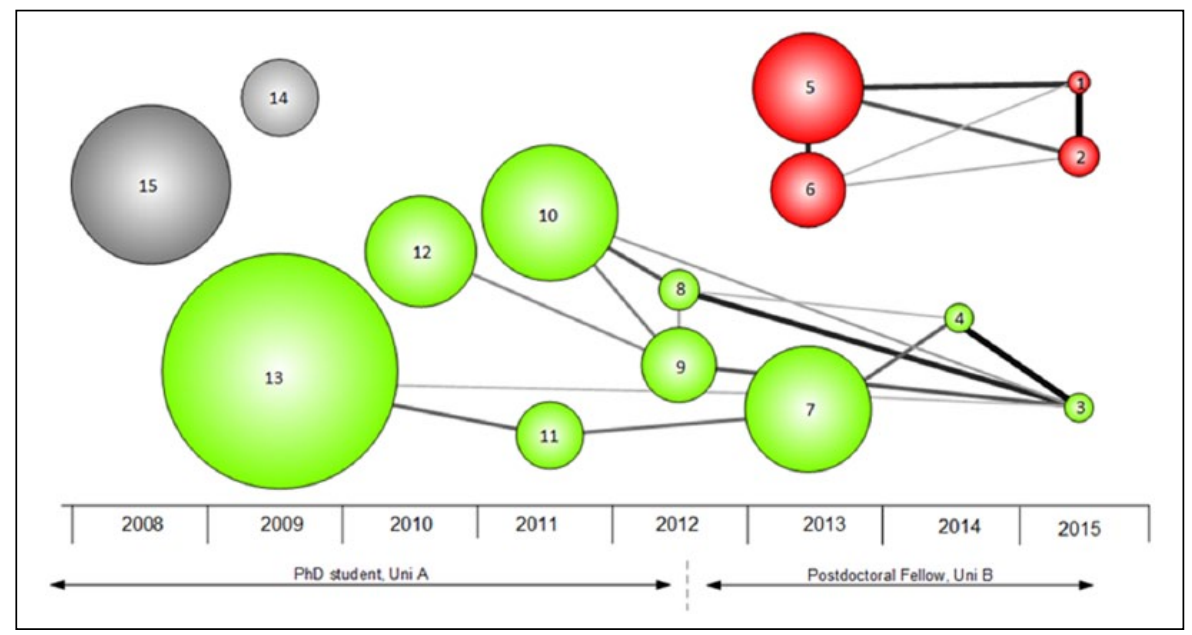

Figure 3. Example of a research trail of an Atomic and Molecular Optics (AMO) physicist.

German early career researchers in three fields. An individual research programme (IRP) is a plan of a researcher for future research that exceeds the scope of a normal project in its thematic breadth and in its duration. The emergences of IRPs is part of the three careers and thus reflected in their scripts.

\section{Methods and data}

Our analysis of career decisions is based on comparative case studies of 56 early career researchers from experimental Atomic and Molecular Optics (AMO) physics and early modern history. Two small fields were selected to minimize the internal variation of epistemic characteristics and scripts. We compared the early career phases of researchers who obtained their $\mathrm{PhD}$ between two and nine years prior to the time of the interview. Most of these researchers held non-tenured positions, which are common in the early career stage in the German system, as postdocs, university assistants, junior group leaders or junior professors.

The case studies are based on semi-structured interviews. The interviews were conducted in the German language (quotations included in this article were translated by us). The interviews consisted of two main parts. In the first part, the interviewee's research and cognitive career were discussed. We used bibliometric methods to reconstruct interviewees' cognitive careers and created visual representations that were presented in the interviews (Figure 3, Gläser and Laudel, 2015a). Based on these representations we explored the development of the interviewee's research since the $\mathrm{PhD}$ project, in particular thematic changes and their reasons. In the second part of the interview, the questions focused on conditions of research and the factors influencing them. In this part we explored the transitions in the organizational career. We asked about the decisions to take 


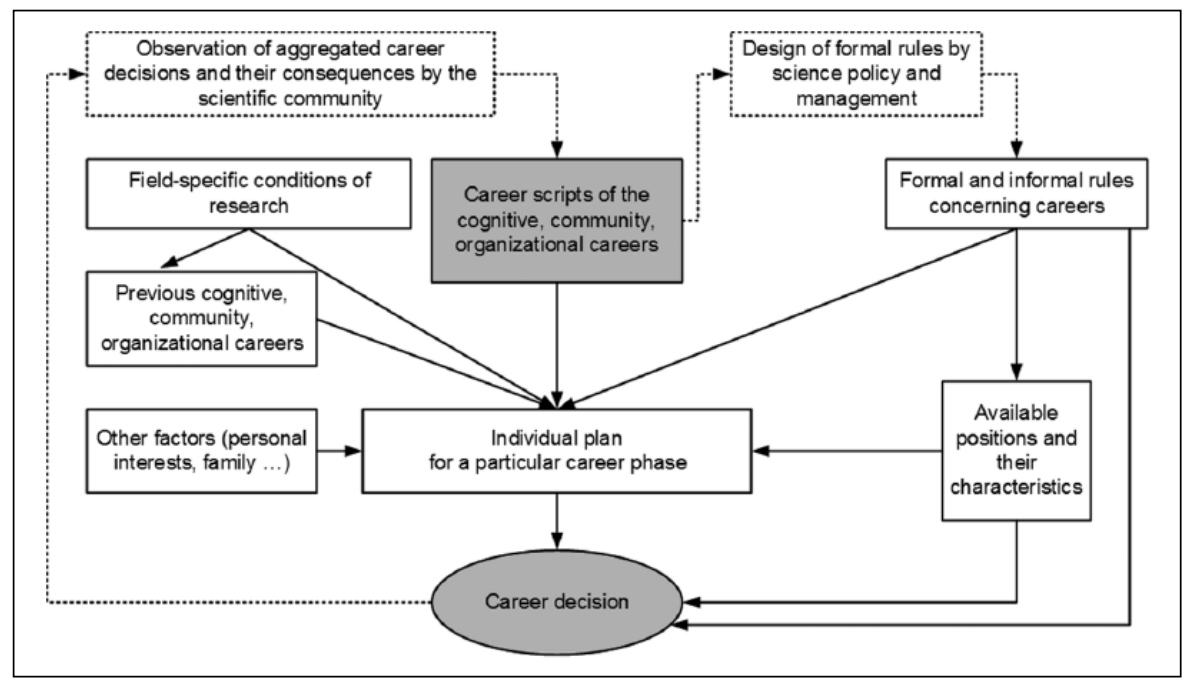

Figure 4. Model of the enactment of career scripts in academic careers (dotted lines indicate causal relationships not considered in the empirical study).

a new position, the respective reasons and potential alternatives. This included opportunities as well as constraints provided by the interviewee's organizational position.

The analysis of the interviews built on a qualitative content analysis (i.e. the extraction of information from the transcripts by assigning it to categories that were derived from our theoretical framework; Gläser and Laudel, 2013). Appendix 1 describes the extraction process. For the analysis of career decisions, the framework included the individual career plan for the next career phase and available positions as immediate influences on career decisions (Figure 4). We assumed these plans to be influenced by the perception of available positions, of rules concerning careers, the researcher's three careers up to the time of the decision, other factors like personal interests or family concerns and scripts for the three careers. The scripts were likely to be field specific (i.e. influenced by the characteristic research practices of the field). In extended time frames, individual career decisions will not only be an enactment of scripts but may also change them if actors respond to changed conditions by making different decisions (Barley, 1989: 54), which is depicted by the arrow with the dotted line.

On the basis of the extracted information, we constructed case histories for all early career researchers, identified field-specific institutions and research practices through comparisons of research processes in each field, and identified relevant general institutions such as definitions of positions, organizational rules of research organizations, and eligibility rules of funding organizations. The comparison of case histories enabled the identification of patterns in careers and of scripts for these careers (Figure 5).

The identification of scripts and their role in career decisions was based on a comparative analysis of decisions. We identified all decisions reported by our interviewees. From the descriptions of these decisions, we extracted information about the decisions' 


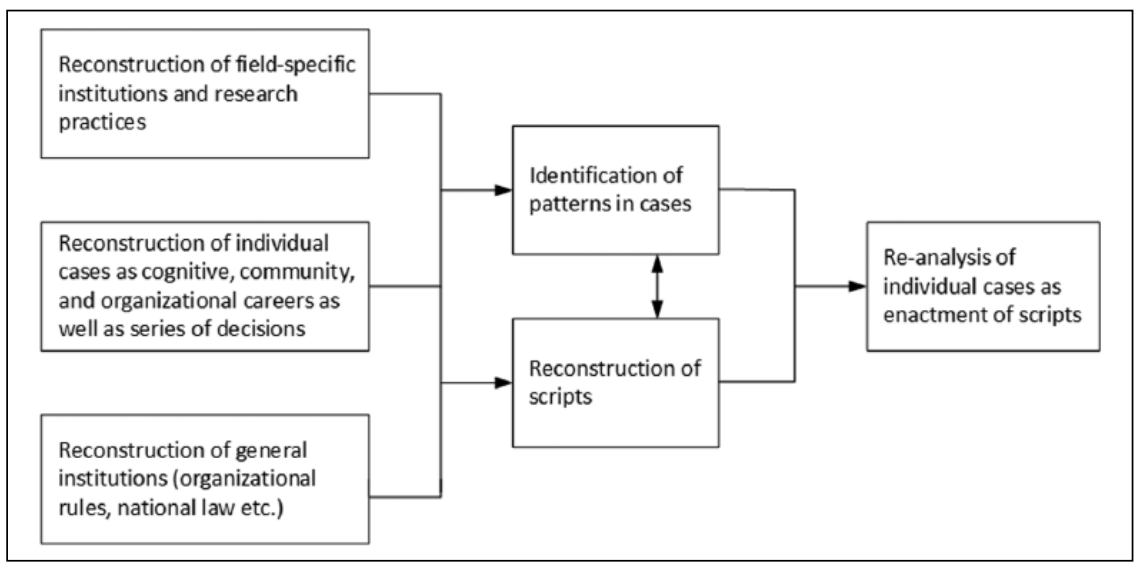

Figure 5. Analytical steps in the identification of scripts.

outcomes, possible alternatives considered by interviewees and reported reasons for selecting one particular option. Reasons were categorized as individual plans, references to scripts, the perception of available positions, preceding career phases, institutional rules, personal interests, family concerns and other factors. For the cognitive career script we searched for reasons that referred to an internal logic of progress in individual plans for knowledge production. The community career script was derived from references to the accumulation of reputation (particularly through publications) and career expectations ascribed to the scientific community as social context. For the organizational career scripts, we searched for patterns in descriptions of properties of organizational positions sought by and offered to researchers. We underline all phrases in quotes that indicate the existence of generalized, collectively held descriptions of successful careers.

\section{The role of career scripts in decisions of German early career researchers in two fields}

We specify the scripts of the cognitive, community and organizational career of researchers in two respects. First, we focus on the early career phase and thus the scripts that guide the search of IRPs. Second, we explicate these scripts for two research fields, AMO physics and early modern history. For each field, the empirical material is organized as follows. We outline the research practices of the field and the characteristics of an IRP. We then identify important institutions and describe the scripts for the three careers. In a next step, we demonstrate the enactment of these scripts in decisions with examples from two early career researchers' decisions. Finally, we examine the conformity of career patterns with the three scripts in each field.

Experimental AMO physics. Research in experimental AMO physics is aimed at answering theoretical questions by manipulating and measuring the behaviour of micro objects 
(from molecules to elementary particles). They are derived from theory and experiments that are designed specifically to answer these questions. Building the needed complex experimental setting usually takes several years.

An IRP in experimental AMO physics is a longer-term research endeavour that is based on such a purpose-built experimental system and aims at answering a set of theoretical questions. The plan consists of a design for such a system and the theoretical idea. It is a combination of theoretical considerations with knowledge of experimental possibilities. Searching for an IRP means learning to master different techniques and finding the theoretical idea. To find the theoretical idea one has to closely follow theoretical discussions in the community and interpret them in the light of one's own experimental experiences. Direct competition can be avoided by modifying an experimental setup so it can answer a unique set of questions.

The institutions governing the cognitive career are the informal rules and expectations of the scientific community. They include rules defining publishable contributions (with an emphasis on journal articles contributing to theory), rules of experimentation including methodological standards, and expectations concerning research programmes (answering sets of interrelated theoretical questions). The cognitive career script emerging from compliance with these rules describes how successful cognitive careers depend on monitoring the theoretical discussions of the field and on using existing experimental settings for testing the methodological implications of theoretical ideas by implementing new manipulation and measurement methods in the experimental setup. It consists of interrelated steps of learning, acquiring theoretical knowledge and experimental testing of ideas. The script includes a close observation of other groups and differentiation of the IRP in order to enable original contributions.

Institutions concerning the accumulation of reputation and associated status passages are again largely informal. Researchers are expected to continuously publish journal articles beginning with their apprentice phase. They are expected to gain independence (i.e. to independently design experiments and research programmes) during their postdoc phase. Master status is linked to presenting a theoretically promising and experimentally feasible research programme. The community script for the phase in which IRPs are searched is one of gaining sufficient reputation to be able to conduct the search and subsequently realize the IRP by passing the peer reviews for positions and grants. For early career researchers from AMO physics this translates into producing publications in prestigious journals on each position, because otherwise the following position would be difficult to obtain. The publication record is also important for obtaining a group leader position, which is necessary for realizing an IRP and for acquiring additional grants. The community script of early career researchers further encompasses the move from the career stage of an apprentice who conducts dependent research to the stage of a colleague who conducts independent research, and then further to the stage of a master who guides PhD students and postdocs. The latter stage is necessary because an IRP cannot be realized without additional research personnel. In the following example, the risk of not being able to publish during the postdoctoral stay affected the career decision:

And this was important to me, too. I knew that a postdoc means going somewhere for two or possibly three years, and that one has to publish during that time, to have something to show. 


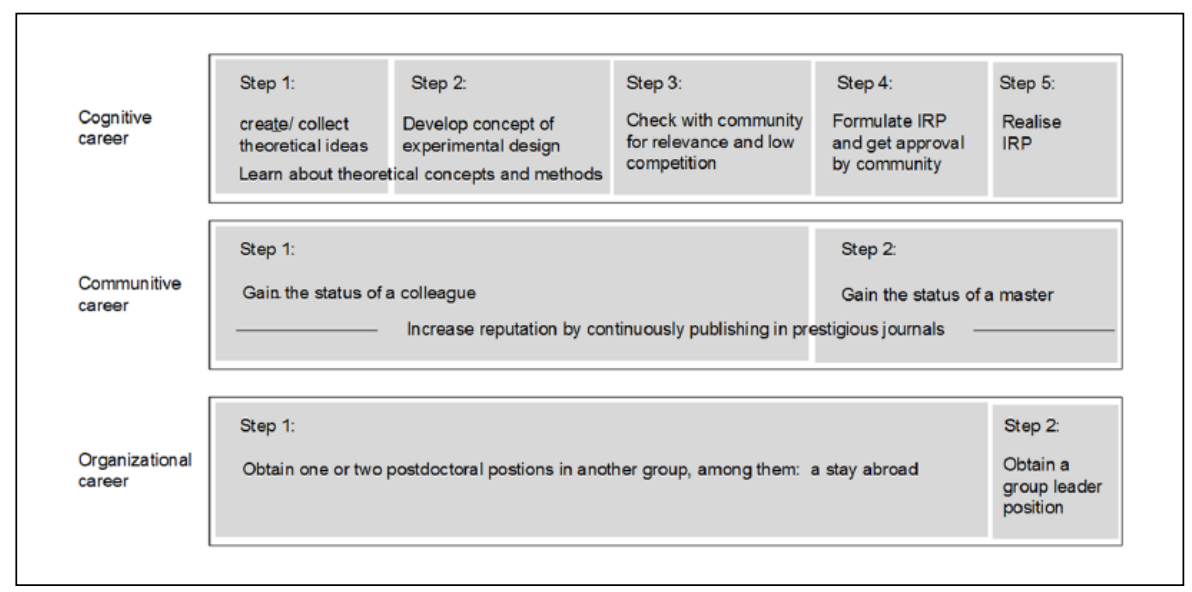

Figure 6. Career scripts in experimental Atomic and Molecular Optics (AMO) physics.

And accomplishing something during that time in Zurich seemed unlikely. And here it is more likely that it works.

The organizational career is based on formal institutions, which include general labour laws, formal structures of research organizations and, particularly, eligibility criteria for organizational positions and external funding. These institutions partly formalize informal rules governing the community career (e.g. when postdoctoral positions are defined as dependent positions in other researchers' groups or when funding of research groups is made pendent on the presentation of a research programme). The script of the organizational career reflects a sequence of organizational positions that is necessary to follow the script for the cognitive career. In AMO physics, the cognitive script of broadening one's knowledge base and searching for an IRP is reflected in a diffuse script of taking up one or two postdoctoral positions and then a move to the position of a group leader on which the first IRP can be realized before finally obtaining a tenured position. The script entails organizational mobility in the postdoctoral phase, which includes international mobility:

And after the $\mathrm{PhD}$ the question arises what to do. It is common to go abroad to a different group and to do a postdoc.

The script both reflects institutions, namely the eligibility rules for junior group leader positions, and is enacted by funding agencies that design these rules. Figure 6 summarizes the three scripts and their alignment. The three careers interact and maintain each other in each of the steps. In the first phase, the postdoctoral positions must support the development of an IRP (i.e. enable the learning). At the same time, they must yield enough publications to ensure success with the next application. When the researchers designed an IRP, the community must approve it, which entails the ascription of master status and the selection for the organizational position of a group leader. 
The following examples illustrate the role scripts play in career decisions. The two cases contain typical ways of reasoning about career decisions of early career AMO physicists.

The first case is an AMO physicist who had to decide twice about postdoctoral positions. His decision for the first postdoc was to spend two years in a laboratory abroad. This decision was influenced by the cognitive, community and organizational script in that order of priorities.

The researcher wanted to learn certain new technologies, which he could connect to his previous $\mathrm{PhD}$ work. He expressed that this is what everybody does:

There I reoriented slightly. This is actually quite typical to try something new after the $\mathrm{PhD}$ thesis, just to learn something different, learn other methods, go abroad.

It was also important to him that the experimental setup in the new group was already up and running and could be used for producing experimental data because this increased the chances to publish journal articles during this period. He expressed the importance of the community script for gaining reputation by first criticizing his $\mathrm{PhD}$ group's experiments for their low yield and then giving the reason for his choice of the postdoc group:

I think if I were group leader in [town of $\mathrm{PhD}$ work], I would eventually abandon the experiment. Because I know that the generation of $\mathrm{PhD}$ students after me suffered enormously, there were few papers, few scientific publications. And this is of course a drawback for the future scientific career.

I also badly wanted to join a running experiment. And well, within two years, two nice papers came out. That was my strategy, I didn't want to do another back-breaking job, but rather something where something is there, where I can contribute.

He searched for a postdoc abroad and applied for positions in several countries. He received some offers which all met his aspirations for the cognitive and community careers. He chose a group because of their outstanding technological expertise and excellent infrastructure. Additional factors that affected the decision included the group's way of working and his interest to learn the country's language:

Well, they have the best [infrastructure] in PhysTown1, especially in terms of . . measurements they are world leaders . . . But also their way of working fascinated me and also personally I liked them ... And since I always wanted to try something new and could not speak [language], I thought I had to go to [country].

The next decision was triggered by information about a postdoc position in an area that met his interests and offered a chance of being turned into an independent group leader position. In this situation, the organizational career script dominated the cognitive career script. He successfully applied for this position. At this time he already had a vague idea (a 'vision') for an IRP based on an experimental system that combined the technological 
knowledge from his $\mathrm{PhD}$ and his postdoctoral work. For realizing this idea he needed to learn yet another technology, which was possible at the new postdoc position:

I used my time at [technology X] to become familiar with the technology. I have never worked with [objects] before. Well, I used this year intensively and learned a lot.

During this second postdoc he began to specify his IRP by developing theoretical concepts for the experimental setup. By planning a new combination of technologies, he ensured that his IRP was sufficiently cognitively distant to all groups he previously had worked in. He then further followed the scripts for the community career (gaining master status) and for the organizational career by (successfully) applying for a group leader position in [PhysTown 3].

We see in this case the scripts for all three careers at work. Several statements by the interviewee and the decisions he made reflect his knowledge about 'how things are done'. The underlined statements are abstract descriptions of 'what everyone does' and thus point to collectively shared knowledge about successful careers.

Our second case is an AMO physicist who searched - after a short postdoc in his $\mathrm{PhD}$ group - for a postdoctoral position abroad. Similar to the first physicist, he made a decision in accordance with the cognitive script, namely to combine his expertise that he had obtained so far with acquiring new technological knowledge. He, too, looked for a group where he could produce publications during the postdoctoral phase.

He applied for several positions abroad because he assumed stays abroad are a prerequisite for later group leader positions. Thus, his decision was informed by three steps of the organizational career script - conducting a postdoc, staying abroad and obtaining a group leader position:

Well, after I decided to do another postdoc, to try to stay in science . . I sent out applications. And I looked at European countries - Austria, Switzerland, France, UK . . And this also for the mundane reason that for further funding, if one wants to apply for an [Emmy Noether group leader position], a formal prerequisite is to have been abroad.

The quote contains both the description of an institution (only researchers with a postdoc stay abroad are eligible for funding of an Emmy Noether group) and a more general reference to 'further funding', which points to the script of an organizational career. From the two offers the researcher received in response to his applications, he selected the group that appeared more promising with regard to the community career script of accumulating reputation:

And the topic, the idea they pursued in PhysTownA was more risky ... And here in PhysTownB, there was already the apparatus for producing cold atoms ... and they were close to measuring something. And this was important for me, I knew, as a postdoc you go for two or three years somewhere and you need to publish during this period, you need to show something ... That's these AMO experiments, it takes two to three years to build the apparatus before you can measure anything.

Personal interests played a role, too: 
Table 2. Patterns of script enactment in Atomic and Molecular Optics (AMO) physics.

\begin{tabular}{llll}
\hline $\begin{array}{l}\text { Number } \\
\text { of cases }\end{array}$ & Cognitive career script & Community career script & Organizational career script \\
\hline 20 & Conform & Conform & Conform \\
6 & Conform or fast track & Fast track & Fast track \\
5 & Non-conform & Conform (publishing) & Non-conform \\
\hline
\end{tabular}

On the other hand, I didn't want to be so far away from Europe, and I am not really in favour of the USA as a research location. So I have restricted myself to jobs in Europe.

He published his first article about his postdoctoral work a year after he started. After that, the experimental work went into a new direction, which required adapting the experiment in a longer trial-and-error phase before new publishable results would be produced:

However, the question arises for me whether I stay here any longer . . . Or if it would be better to do something new. That's what I am contemplating at the moment. You have to run a bit on sight, always having the next two or three years in mind. If I had something where I knew that I could achieve a fantastic result in one or two years, then I would be more prone to stay here. Otherwise, if this will be a lengthy dry spell then I have to consider, from the point of view of $\mathrm{CV}$, the later career, if that still benefits me.

At the time of the interview, the physicist had to make a decision about his next step in the organizational career. His careers were de-synchronized in that although he had succeeded in broadening his technological knowledge, he had not yet found a theoretical question and an idea for an experimental design sustaining an IRP:

I have a concrete offer which is very tempting. [The position] . . is in Germany, and has the perspective of a permanent position ... and I am thinking intensively about accepting this. Because the alternative is to stay here and to hope that the [experiment] produces results and that the publication list is sufficient for competing with other postdocs for a professorship. These are the many uncertainties if I would stay here and proceed on this path, although . . . it would be a path to a future that is more independent, but a more uncertain path.

The interviewee faced the decision to deviate from the organizational career script by trading the sequence of positions that eventually enables the master status of the community career for a permanent position with unknown opportunities for independent research.

Having identified the three career scripts and having illustrated how they operate in career decisions, we now turn to the extent to which scripts were enacted by our interviewees. Table 2 provides an overview of our cases. In the majority of these cases, career decisions, career progress and personal plans of interviewees conformed to the three career scripts, and their movements through the three careers were aligned as shown in Figure 4. We observed two interesting deviations from that pattern. A first deviation can 
be characterized as fast track. It includes researchers who knew about the career scripts but didn't enact them the same way the majority did. These six interviewees developed their IRP during their PhD or soon after and gained their master status and the position of a group leader without going through all the steps of the organizational career script. They all responded to opportunities (i.e. to a situation where the elite of their field made positions available at an earlier stage of their organizational career because they were well advanced in their cognitive and community careers).

Not all researchers enacted scripts of a continuing academic career. Three researchers planned to leave academia. They did not develop an IRP but just conducted dependent research and published. Owing to the low number of cases and the focus of the investigation, we do not have enough information to decide whether there are exit scripts for AMO physicists. Two other researchers did not enact the scripts because they preferred a continuation of their current dependent research to developing an IRP, becoming an independent researcher and becoming a group leader. Both were aware that this is close to impossible at German universities because there are almost no permanent positions below the professorial level.

Early modern history. Research in early modern history is aimed at answering questions about societies in a specific region at a time period within or coextensive with early modernity. Researchers use archival sources in order to develop original arguments. Data collection is thus centred on archival work, while developing arguments consists of analysing and interpreting sources as well as developing arguments through writing.

An IRP in early modern history is a longer-term endeavour of answering a question about a regionally and temporally bounded empirical object (i.e. a society in a specified region and a specified time period). Developing an IRP involves delineating an object and formulating a new relevant question about it that can be answered based on existing archival material. Part of that is to check the availability of sources and their yield for making the intended historical argument. Whether a topic is sufficiently substantial in these respects and the IRP sustainable may only become apparent after a lengthy process of reviewing the literature and sources. Although there is little direct competition in early modern history, researchers face the risk of redundancy (i.e. of not being able to say anything new on a topic on the basis of the same archival sources). Thus, relevance and originality of the question must then be tested.

The scientific community's informal rules concerning cognitive career emphasize independence (i.e. developing an IRP that is different from those of all other historians). A strong informal rule is that the IRP must lead to a second book, which in Germany is the habilitation thesis. A specific rule of the German community, which is enforced when the venia legendi is awarded, concerns the relationship between the $\mathrm{PhD}$ topic and the topic of the habilitation thesis). ${ }^{3}$ The two topics must be different in terms of time period and region.

The cognitive career script for developing an IRP describes the search for empirical objects by using one's personal repository of previously collected sources and by reading the published literature. When an object is found, the script consists of several connected processes. The object must be tested for its 'usability' (i.e. the existence of sufficient sources for the generation of data). It must be delineated thematically, in terms of region 
and time, which means for German early career researchers to substantially broaden their topical range, by moving away from their $\mathrm{PhD}$ work in all three aspects:

I started this for the 1640 s, i.e. the 17 th Century, and people said 'ok, but you need to go into the 16th or the 18th Century' ... Well they always told us the rule of thumb for habilitation projects is different topic, different century, this is how it's like in history.

This quote describes the content of the script, demonstrates its nature as a generalized description of career steps, and indicates that scripts are collectively shared (communicated about). In connection with the delineation of an object, one or more questions about it must be developed. Finally, historians need to observe their community's research in order to avoid redundancy.

Rules concerning the accumulation of reputation and associated status passages say that major arguments (the PhD and habilitation theses) must be published as books. Books (and favourable reviews by peers) are the major source of reputation in the field. Consequently, the community career script includes the process of preparing one's $\mathrm{PhD}$ thesis as a book publication. In addition, early career researchers are expected to continuously produce minor publications on the $\mathrm{PhD}$ topic and to review other books on their $\mathrm{PhD}$ topic as well as on their new topic to mark their expertise in a certain area. Although historians already work largely independently during their $\mathrm{PhD}$ (e.g. by selecting their own research question), they still are guided by experienced researchers. This is why the post- $\mathrm{PhD}$ community career script still includes a status change from apprentice to colleague, with which this kind of guidance disappears. Since historians don't work in groups, the next stage (master status) is not necessary to realize an IRP.

There are very few rules governing the organizational career. All organizational positions that somehow support the development of an IRP are acceptable. This is why the organizational script in history is rather diffuse: at least one fixed-term position must be taken up before an early career researcher can apply for a tenured position (which is in Germany a full professorship). However, the type of position is not specified. It is important to move away from one's $\mathrm{PhD}$ supervisor at some point:

Actually, what I am doing here is a bit queasy. Commonly, a change of place is obligatory, and not doing it can be seen as wheeling and dealing - I am fully aware of that.

The quote refers both to an informal rule in the scientific community ('is obligatory') and to the generalized practice ('commonly'). As in physics, organizational mobility during the early career phase is part of the script. Stays abroad were considered advantageous by many of our interviewees, some of which even reported it as their community's expectation. However, this expectation is (still) too weak to have entered the organizational career script. Figure 7 summarizes the scripts.

Again, we illustrate the role of these scripts in career decisions with two examples. Our first example is an early modern historian who after her $\mathrm{PhD}$ faced the tasks of simultaneously developing an IRP that is sufficiently different from her $\mathrm{PhD}$ (cognitive career script), publishing her $\mathrm{PhD}$ thesis as a book (community career script), and finding a position on which both could be done (organizational career script). The latter was 


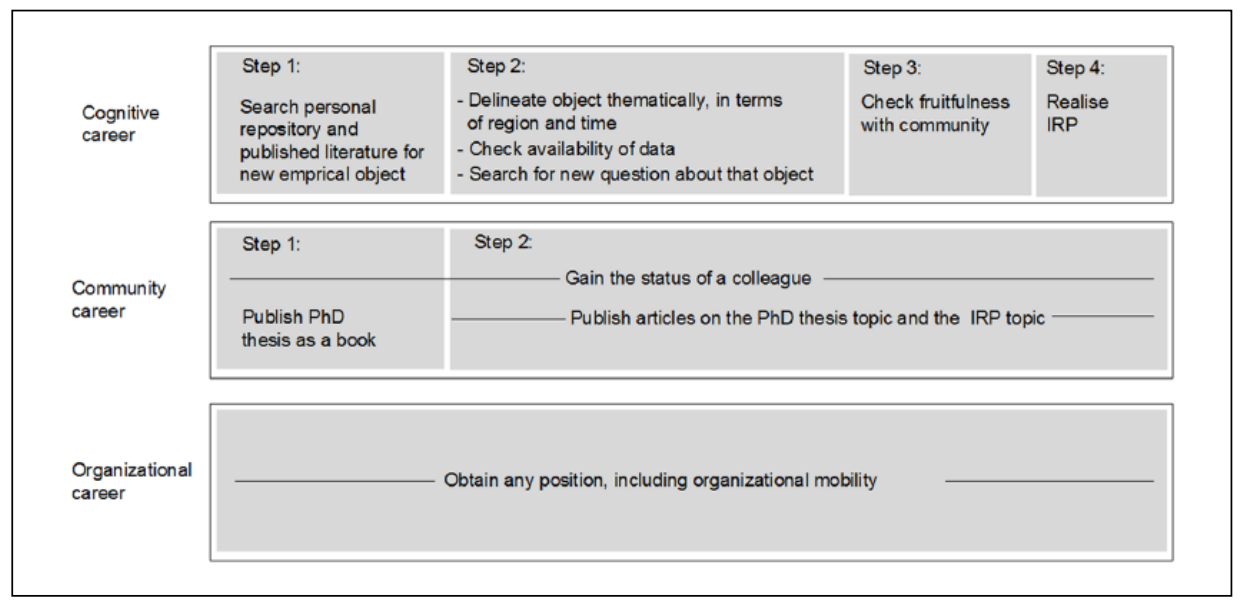

Figure 7. Career scripts in early modern history.

particularly problematic because academic positions for early career researchers in history are exceedingly rare. Our historian had to compromise by taking up a postdoctoral position within a research project conducted by a professor. While she could enact the organizational career script this way, her particular position was at odds with the cognitive and community career scripts because the topic of her research was already specified by others. She had to accept this topic rather than being able to select it:

Well, you can deal with anything. If you engage with something for some time then it becomes interesting. It was simply practical to do that. Often, after having finished the $\mathrm{PhD}$ and the contract expires then you end up on the street. And that's why I thought [this position] would be good for the transition time afterwards.

The comment 'often ... you end up on the street' refers to the possibility of temporarily continuing the career on non-academic employment or even unemployment benefits, which happens because the organizational career script is difficult to follow due to the scarcity of academic positions. The topic of the project that came with the postdoctoral position set an overall thematic framework but left her considerable room to shape it according to her interests. She soon went to the archives to look what sources were available to investigate this topic. However, this turned out to be a sobering experience:

There I was mainly in the National Archive and looked at letters . . But nothing really came out of it ... the sources did not yield much information. But I didn't know that in advance ...

The sources in the archive had already been extensively used and were somehow exhausted for this topic. She realized that the new topic would not be substantial enough for an IRP. Still, the historian was able to revise her $\mathrm{PhD}$ thesis and prepare it for publication as a book and to publish a few articles about the new topic (i.e. to follow the community script). At the end of this postdoctoral position, she thus faced a situation in 
which she had advanced according to the community career script but still was in the same situation as after her $\mathrm{PhD}$ with regard to her cognitive career.

In this situation, she applied widely for various academic and non-academic positions. She secured a fixed-term research and teaching position at the same university department. During a second archival stay of several months she discovered sources that inspired her to radically change the focus of her topic. She defined a new object that had been neglected by other historians. The abundance of sources let her decide that this would be the topic for her IRP and second monograph. With reference to the cognitive script she selected the time period and region in a way that they were completely distant from the topic of her PhD thesis:

And that's recommended everywhere that you do a completely different topic for the second book ... which is temporally, geographically as well as thematically completely different. Yeah, and that's what it is exactly: it really has almost nothing to do with the [PhD topic] except ... that I still approach it microhistorically.

Our second example is similar in that the tight labour market for historians left the researcher little choice. He successfully applied for a two-year postdoctoral position in a research cluster. Again, this was a compromise between the cognitive career script, on the one hand, and the community and organizational career scripts, on the other hand. The historian was interested in the overall topic that was pre-defined for this postdoctoral position but was not sure that the topic would be substantial enough to sustain an IRP. Since he needed a position where he could work on publishing the PhD thesis as a book, he began developing the topic to which the position was bound. At the end of his postdoctoral stay he had published his $\mathrm{PhD}$ and had considerably changed the focus and breadth of this topic in order to make it substantial enough for an IRP. He had checked the available sources in libraries and archives to make sure that this IRP had an adequate empirical basis. The development of the topic also followed the cognitive script by being sufficiently different from the $\mathrm{PhD}$ thesis:

The connection is very loose . . If you compare this with studies in the UK that emerge from the first book [the PhD thesis] then it is much more obvious in the historical sciences that you try further explore the topic and emphasize the connections. I didn't do that. And I think that it is uncommon in the German system of historical science . . . because they want you to show breadth. That is, change the century, choose another topic, and demonstrate that you are capable of gaining expertise in different areas.

With this topic, the historian moved to another two-year postdoctoral position and subsequently to a fixed-term research and teaching position. Both positions enabled him to realize his IRP by conducting research on the second monograph. On all these positions, the historian further pursued his $\mathrm{PhD}$ topic and continuously published articles, and he also began to publish on the new topic. The change of universities for each of the three positions was not triggered by the mobility expectation built into the organizational career script, instead it seemed to be a side effect of the labour market for early modern historians. 
Table 3. Patterns of script enactment in early modern history.

\begin{tabular}{llll}
\hline & Cognitive career script & Community career script & Organizational career script \\
\hline 22 & Conform & Conform & Conform \\
1 & Conform & Conform & Non-conform \\
2 & Exit & Exit & Exit \\
\hline
\end{tabular}

The overwhelming majority of historians' careers conformed to the three scripts (Table 3).

The degree of conformity, which is even higher than that of AMO physicists, can be explained by the diffuseness of the organizational script and its loose coupling with the cognitive script. If the development of an IRP does not depend on particular properties of organizational positions, it is rather difficult for a career not to conform to the organizational script as long as the organizational mobility is enacted. The only interesting deviation was indeed the case of a historian who did not move away from the organization at which he did his $\mathrm{PhD}$ (and knew he was not enacting the script, see the quote above, p. 19).

Two more historians planned to leave academia. Again, it is impossible to say whether they enacted a particular set of scripts because we do not have enough information about collectively shared knowledge about sequences of steps successfully leading to that in the three careers.

\section{Discussion}

Although career studies using the script concept appear to rely on the same definition, they have interpreted this definition in a variety of ways, and have used 'script' mostly as a descriptive label. We agree with Valette and Culié (2015) in that the most productive use of the script concept depends on understanding it as an interpretive scheme. This definition is more specific than those offered by Barley and can be grounded in a theory of action. We defined career scripts as collective scripts that encode sequences of stages within a career and decisions that are likely to produce these sequences when made in specified situations in a specific institutional setting. In contrast to Valette and Culié, we treat career scripts as strictly collective-level phenomena. Owing to their link to a specific institutional setting, career scripts are also specific to a social context. Since academic careers proceed in two social contexts simultaneously (the scientific community and the employment organizations), and since they are strongly influenced by the diachronic structures of knowledge production processes that unfold over time, academic careers are best captured by a model that analytically distinguishes three sequences of work experience and treat them as separate careers, each of which has its own scripts.

We were able to obtain information about collectively shared scripts from individual accounts in three different ways. First, some descriptions of decisions included references to scripts as factors influencing these decisions. As the quote in the title of this article and the interview quotes in the text indicate, interviewees referred to 'the way in which things are done' if one wants to have a successful career. We underlined all phrases 
in the quotes that refer to these generalized descriptions of successful careers. References to the same descriptions in different interviews and references to the communication of such descriptions made clear that they are collectively shared.

Second, scripts were described as expectations of the community. Typical phrases in interviews included 'it is expected' or 'it is expected by the community'. These descriptions sometimes refer to both institutions and scripts mediating between institutions and individual actions. When no rule was described and no actor was specified in a description of expectations, we considered them as representations of scripts.

Third, we derived the existence of scripts from decisions that were not made. In many descriptions of decisions, no explicit reference to scripts was made. This is not surprising because interpretive schemes are not necessarily consciously applied. However, the third and most important indication of the operation of scripts were many decisions reported by interviewees that simply conformed to the scripts. No interviewee reported looking for a professorial or group leader position without having an IRP. None of the AMO physicists applied for a group leader position immediately after their $\mathrm{PhD}$ without being asked to do so (in the 'fast track' cases). In other words: the many career decisions the researchers could have made but didn't are the clearest indicator of their awareness of scripts.

The role of scripts as mediating between institutions and individual decisions is much more difficult to show than the operation of scripts in decisions. The main reason for this is that scripts often mediate the influence of institutions on actions by hiding the institutions. Scripts make it possible for researchers to respond to institutions proactively (i.e. before they encounter a rule that prescribes and sanctions behavior). For example, all AMO physicists decided to go abroad for at least one postdoctoral stay long before they encountered eligibility rules that would let only those who did apply for funding for research groups.

This analysis led us to the conclusion that early career researchers indeed enact scripts when they make decisions about their careers. More precisely, they enact certain parts of scripts that are relevant to their career stage but do so in the light of the whole script. This makes scripts one of several factors influencing career decisions. Other factors like the availability of positions and their characteristics (in terms of autonomy, resources and time for research), the availability of organizational positions, and considerations beyond academia such as preferences for countries or languages as well as other interests and family concerns also affect career decisions and may override scripts.

Nevertheless, the analysis of individual career decisions and of career patterns shows that scripts played an important role in the physicists' and historians' career decisions. This makes their career decisions appear incredibly rational. However, they have to be so rational because a successful career would otherwise be unlikely. Career studies agree that contemporary academic careers are marked by fierce competition for tenured positions (e.g. Fochler et al., 2016; Lam and De Campos, 2015), which strengthens the role of scripts for successful careers.

The scripts correspond to field-specific epistemic practices. In AMO physics, the theory-driven nature of the experimental research and the long time it takes to build a new experiment contribute to the cumulative nature of IRPs and the cognitive career scripts leading to them. Early career researchers' cognitive careers follow a pattern of 
extending the methodological skills they acquired in their $\mathrm{PhD}$ projects and combining them with theoretical ideas, while their community careers are realized through a careful selection of positions that will yield publications. Thus, organizational positions are chosen in the light of requirements of the other two careers.

In contrast, cognitive, community and organizational careers of early modern historians are largely decoupled from each other. The cognitive career script suggests finding an IRP that is sufficiently different from the PhD topic. The community career script is very specific in its emphasis on the publication of the $\mathrm{PhD}$ thesis as a book, and on accompanying smaller publications (on the $\mathrm{PhD}$ and on new topics) that secure the reputation necessary for obtaining new positions. The organizational positions themselves are rather unimportant - any position will do. Only positions that prescribe a specific work content may force historians to strike a compromise between their own interests and demands of organizational positions.

We observed that scripts vary in terms of their specificity. In both AMO physics and early modern history we found rather specific scripts for the cognitive career while the script of the organizational career was relatively diffuse for physics and very diffuse for history.

The close links between career scripts and the epistemic practices of a research field makes them specific to these fields. However, this also means that other fields with similar epistemic properties feature similar career scripts. A study of other subfields of history supports this assumption (Laudel, 2017). Accordingly, the scripts of experimental AMO physics are likely to be representative of other areas of experimental physics.

\section{Conclusions}

With this article, we demonstrated that introducing scripts as an explanatory factor contributes to our understanding and explanation of career decisions of early career researchers. We defined career scripts as collective interpretive schemes that encode sequences of actions within a career. They represent steps of commonly successful careers in a certain institutional setting. By defining scripts as specific interpretive schemes, we subsumed it to a specific concept in social theory and avoided conceptual ambiguities introduced by Barley and some scholars who used his concepts. Specifying career scripts as collective phenomena made it possible to distinguish between career scripts, individual career plans and individual career orientations.

Applying this concept in empirical analyses required a further operationalization that takes into account the specificity of academic careers. By introducing a model that analytically distinguishes three careers of a researcher, we were able to specify scripts for each of those careers. We applied these theoretical considerations to an empirical study of the early career phase in two different research fields. We could confirm our assumption that a specific script exists for each of the three careers. Our comparative investigation of early careers in different fields also showed that career scripts for the early career are field specific.

Together, these three specifications made it possible to empirically identify the collective perceptions about careers that are enacted in individual career decisions. We showed 
that all three career scripts are enacted simultaneously in career decisions, and that the specific weight given to each script depends on the decision situation faced by early career researchers. When the three careers become de-synchronized or one of the scripts turns out to be difficult to follow, researchers need to strike a compromise between them. Future research is required for in-depth studies of internal relationships between the three scripts when they are enacted in career decisions.

While our empirical investigation was focused on career paths within academia, it also pointed to the existence of an 'exit script' for leaving academia and moving to neighbouring labour markets. Lam and De Campos (2015) showed that researchers with long postdoctoral phases may consciously develop a different career trajectory that deviates from the prescribed steps of the 'normal career'. This suggests that scripts for different career orientations may coexist in certain career phases.

Finally, our conceptual approach and empirical findings suggest that analytically distinguishing parallel careers of individuals who simultaneously change their positions in different social contexts might be a useful heuristics for the study of other careers, too. This has already been suggested for professional careers. Since scripts are explanatory factors for career decisions, considering parallel scripts and their interaction is likely to improve our understanding of these careers.

\section{Acknowledgements}

We are indebted to the Write Club of the Institute of Sociology at the TU Berlin, to four anonymous reviewers and to Amanda Shantz, the Associate Editor of Human Relations, who all helped to substantially improve earlier versions of this article.

\section{Funding}

This research was supported by funding from the German Federal Ministry of Education and Research (grant number: FoWin004).

\section{Notes}

1 To illustrate our point, we briefly consider treating scripts as institutions, a move that is supported by the wide concept of institutions advanced by the new institutionalism. If institutions are considered as 'social order or pattern', with order or pattern being 'standardized interaction sequences' (Jepperson, 1991: 145), as including 'wider belief systems', 'cultural frames' and 'common scripts' (Scott, 2008: Ch. 3), shared perceptions of successful career patterns would come under this heading. If a narrow definition of institutions as systems of formal and informal rules is applied (North, 1990; Scharpf, 1997), shared perceptions would be something else besides institutions. Any explanations of career decisions that states 'career decisions are influenced by institutions' and uses the wide concept of institutions immediately begs the question about the relative roles of 'institutions that are rules' and 'institutions that are scripts', which is why it is better to distinguish the two from the beginning.

2 For an extended version see Laudel and Gläser (2008) and Gläser and Laudel (2015b). Empirical applications can be found in Höhle (2015), Laudel (2017), Laudel and Gläser (2008) and Wöhrer (2014).

3 The venia legendi is the authorization to teach a specific subject, which still is a de facto prerequisite for becoming a professor of history at German universities. 


\section{References}

Aaltio I and Huang J (2007) Women managers' careers in information technology in China: High flyers with emotional costs? Journal of Organizational Change Management 20(2): 227-244.

Abelson RP (1981) Psychological status of the script concept. American Psychologist 36(7): 715729.

Arthur M, Inkson K and Pringle J (1999) The New Careers: Individual Action and Economic Change. London: SAGE.

Arthur MB and Rousseau DM (1996) Introduction: The boundaryless career as a new employment principle. In Arthur MB and Rousseau DM (eds) The Boundaryless Career: A New Employment Principle for a New Organizational Era. New York: Oxford University Press, $3-17$.

Barley SR (1986) Technology as an occasion for structuring: Evidence from observations of CT scanners and the social order of radiology departments. Administrative Science Quarterly 31(1): 78-108.

Barley SR (1989) Careers, identities, and institutions: The legacy of the Chicago School of Sociology. In Arthur MB, Hall DT and Lawrence BS (eds) Handbook of Career Theory. New York: Cambridge University Press, 41-66.

Barley SR (2015) Why the internet makes buying a car less loathsome: How technologies change role relations. Academy of Management Discoveries 1(1): 5-34.

Barley SR and Tolbert PS (1997) Institutionalization and structuration: Studying the links between action and institution. Organization Studies 18(1): 93-117.

Baruch Y and Hall DT (2004) The academic career: A model for future careers in other sectors? Journal of Vocational Behavior 64(2): 241-262.

Chubin DE and Connolly T (1982) Research trails and science policies. In Elias N, Martins H and Whitley R (eds) Scientific Establishments and Hierarchies. Dordrecht: Reidel, 293-311.

Dalton GW, Thompson PH and Price RL (1977) The four stages of professional careers - a new look at performance by professionals. Organizational Dynamics 6(1): 19-42.

Dany F, Louvel S and Valette A (2011) Academic careers: The limits of the 'boundaryless approach' and the power of promotion scripts. Human Relations 64(7): 971-996.

DeFillippi R, Arthur MB and Lindsay VJ (2006) Knowledge at Work: Creative Collaboration in the Global Economy. Malden, MA: Blackwell.

Duberley J, Cohen L and Mallon M (2006) Constructing scientific careers: Change, continuity and context. Organization Studies 27(8): 1131-1151.

Evetts J (1992) Dimensions of career: Avoiding reification in the analysis of change. Sociology 26(1): 1-21.

Fochler M, Felt U and Müller R (2016) Unsustainable-growth, hyper-competition, and worth in doing research: Narrowing regimes of valuation in doctoral and postdoctoral life scientists' work and lives. Minerva 54(2): 175-200.

Giddens A (1979) Central Problems in Social Theory: Action, Structure, and Contradiction in Social Analysis. Berkeley, CA: University of California Press.

Gioia DA and Poole PP (1984) Scripts in organizational behavior. Academy of Management Review 9(3): 449-459.

Gläser J and Laudel G (2013) Life with and without coding: Two methods for early-stage data analysis in qualitative research aiming at causal explanations. Forum Qualitative Sozialforschung / Forum: Qualitative Social Research 14(2): Art. 5.

Gläser J and Laudel G (2015a) A bibliometric reconstruction of research trails for qualitative investigations of scientific innovations. Historical Social Research - Historische Sozialforschung 40(3): 299-330. 
Gläser J and Laudel G (2015b) The three careers of an academic. ZTG Discussion Paper 35/2015. Berlin: TU Berlin, Center for Technology and Society. Available at: https://www.tu-berlin.de/ fileadmin/f27/PDFs/Discussion_Papers/35_2015discussion_paper_Nr_35_Glaeser_Laudel. pdf (accessed May 28th 2018).

Goffman E (1959) The Presentation of Self in Everyday Life. New York: Anchor Books.

Goffman E (1974) Frame Analysis: An Essay on the Organization of Experience. Cambridge: Cambridge University Press.

Gunz H (1989) The dual meaning of managerial careers: Organizational and individual levels of analysis. Journal of Management Studies 26(3): 225-250.

Gunz H and Mayrhofer W (2018) Rethinking Career Studies: Facilitating Conversation across Boundaries with the Social Chronology Framework. Cambridge: Cambridge University Press.

Gunz H, Mayrhofer W and Tolbert P (2011) Career as a social and political phenomenon in the globalized economy. Organization Studies 32(12): 1613-1620.

Hall DTA (1996) The Career is Dead - Long Live the Career: A Relational Approach to Careers. San Francisco, CA: Jossey-Bass.

Höhle E (2015) From apprentice to agenda-setter: Comparative analysis of the influence of contract conditions on roles in the scientific community. Studies in Higher Education 40(8): $1423-1437$.

Hughes E (1958) Men and Their Work. Westport, CT: Greenwood Press.

Inkson K, Gunz H, Ganesh S and Roper J (2012) Boundaryless careers: Bringing back boundaries. Organization Studies 33(3): 323-340.

Jacobson SW and Aaltio-Marjosola I (2001) 'Strong' objectivity and the use of Q-methodology in cross-cultural research contextualizing the experience of women managers and their scripts of career. Journal of Management Inquiry 10(3): 228-248.

Jepperson RL (1991) Institutions, institutional effects, and institutionalism. In: Powell WW and DiMaggio PJ (eds) The New Institutionalism in Organizational Analysis. Chicago, IL: University of Chicago Press, 143-163.

Lam A and De Campos A (2015) 'Content to be sad' or 'runaway apprentice'? The psychological contract and career agency of young scientists in the entrepreneurial university. Human Relations 68(5): 811-841.

Laudel G (2017) How do national career systems promote or hinder the emergence of new research lines? Minerva 55(3): 341-369.

Laudel G and Gläser J (2008) From apprentice to colleague: The metamorphosis of early career researchers. Higher Education 55(3): 387-406.

Mallon M, Duberley J and Cohen L (2005) Careers in public sector science: Orientations and implications. $R \& D$ Management 35(4): 395-407.

Mayrhofer W, Meyer M and Steyrer J (2007) Contextual issues in the study of careers. In: Gunz H and Peiperl MA (eds) Handbook of Career Studies. Thousand Oaks, CA: SAGE, 215-240.

North DC (1990) Institutions, Institutional Change and Economic Performance. Cambridge: Cambridge University Press.

Scharpf FW (1997) Games Real Actors Play: Actor-Centered Institutionalism in Policy Research. Boulder, CO: Westview Press.

Schütz A (1967) The Phenomenology of the Social World. Evanston, IL: Northwestern University Press.

Schütz A and Luckmann T (1973) The Structures of the Life-world, Vol. 1. Evanston, IL: Northwestern University Press.

Scott WR (2008) Institutions and Organizations: Ideas, Interests, and Identities, 3rd edn. London: SAGE. 
Tams S and Arthur MB (2010) New directions for boundaryless careers: Agency and interdependence in a changing world. Journal of Organizational Behavior 31(5): 629-646.

Valette A and Culié J-D (2015) Career scripts in clusters: A social position approach. Human Relations 68(11): 1745-1767.

Weick KE (1996) Enactment and the boundaryless career: Organizing as we work. In: Arthur MB and Rousseau DM (eds) The Boundaryless Career: A New Employment Principle for a New Organizational Era. New York: Oxford University Press, 40-57.

Whitley R and Gläser J (2014) The impact of institutional reforms on the nature of universities as organisations. In: Whitley R and Gläser J (eds) Organizational Transformation and Scientific Change: The Impact of Institutional Restructuring on Universities and Intellectual Innovation, Vol. 42. Bingley: Emerald Group, 19-49.

Wöhrer V (2014) To stay or to go? Narratives of early-stage sociologists about persisting in academia. Higher Education Policy 27(4): 469-487.

Zabusky SE and Barley SR (1997) 'You can't be a stone if you're cement': Reevaluating the emic identities of scientists in organizations. Research in Organizational Behavior 19: 361-404.

Zikic J and Richardson J (2016) What happens when you can't be who you are: Professional identity at the institutional periphery. Human Relations 69(1): 139-168.

Grit Laudel is a senior researcher in the Department of Sociology at the Technical University Berlin. She is a sociologist of science who investigates the influence of institutions on the conduct and content of research. Currently she explores how early career researchers in different research systems become independent. [Email: Grit.Laudel@tu-berlin.de]

Jana Bielick had been a research associate in the Department of Sociology at the Technical University Berlin, investigating academic careers. She enacted an exit script and left academia. [Email: Jana.Bielick@tu-berlin.de]

Jochen Gläser is a senior researcher at the Center for Technology and Society of the Technical University Berlin. His major research interest is the interaction of epistemic and institutional factors in the shaping of conduct and content of research at the micro-level of individuals and groups and at the meso-level of scientific communities. [Email: Jochen.Gläser@ztg.tu-berlin.de]

\section{Appendix I. Description of qualitative content analysis}

The qualitative content analysis applied in this study differs significantly from coding texts, which can be considered as the mainstream of qualitative data analysis. Instead of attaching codes to text segments and later using the codes for selective retrieval and additional analysis or for developing themes, qualitative content analysis extracts information from texts by using categories as extraction tools (Gläser and Laudel, 2013). Categories are based on the concepts from the theoretical framework, but can be changed and added to in order to capture information that was not anticipated by the theoretical framework.

Categories contain the dimensions of the concepts, a time dimension capturing for which point in time or period of time information was provided, and causal dimensions capturing causes or effects of phenomena as they are reported by interviewees. They are used for retrieving and thematically storing information from the interviews. We demonstrate this extraction of information with an example. The category 'development of 
organizational career' was used to extract information about the sequence of organizational positions and decisions about positions (decisions to apply, success of applications, decisions to accept positions). It was constructed as follows:

- 'time' extracted the time for which information was reported;

- 'topic' extracted information about the research topic(s) the interviewee worked on while on the position;

- 'subject matter of action' extracted information about the subject matter of decisions (application, acceptance of position and so on);

- 'content of action' extracted information on the position for which the interview applied /which they accepted and so on;

- 'reported causes' extracted information on all reported causes for the action including reasons given by the interviewee for applying, accepting a position and so on;

- 'reported effects' extracted information on all reported effects of the action:

- 'source' captures the identification about the paragraph from which information was extracted (file name and number of paragraph).

We demonstrate the extraction process with an example from an interview with a physicist:

PDa8-81\# This is only because I had done my $\mathrm{PhD}$ for four years and subsequently was a postdoc for four years. It is simply time to add another place if I go for an academic career, which I certainly do. This is why it is simply logical to move to somewhere else, so to speak. In a sense, it was quite unusual that I stayed at this experiment for so long. Which really was due to this experiment, which I still think is very very good. But now it is time for me to add another place. So I will move to [Phystown] sometime at the beginning of the next year, and will work in a somewhat similar area. It is a slightly different question but more or less the same techniques are applied.

Information from this paragraph was extracted as follows:

\begin{tabular}{lllll}
\hline Time Topic & $\begin{array}{l}\text { Subject } \\
\text { matter of } \\
\text { action }\end{array}$ & $\begin{array}{l}\text { Content of Reported causes } \\
\text { action }\end{array}$ & $\begin{array}{l}\text { Reported } \\
\text { consequences }\end{array}$ & Source \\
\hline 2014 & $\begin{array}{l}\text { Position } \\
\text { (acceptance) }\end{array}$ & $\begin{array}{l}\text { Postdoc, } \\
\text { change to } \\
\text { Phystown }\end{array}$ & $\begin{array}{l}\text { Interviewee was in the same } \\
\text { group for 8 years, change is } \\
\text { necessary for career, new } \\
\text { group works in a similar } \\
\text { area (slightly different } \\
\text { question, same techniques) }\end{array}$ & |PDa8-8II \\
& & &
\end{tabular}


Please note that information about the time was given in a previous paragraph, and was carried over in order to be better able to link this row with other rows describing decisions.

The information stored in tables was used to reconstruct careers, research practices, institutions, and scripts as described in the methods section. 